\title{
PEMBELAJARAN BANGUN RUANG BERBASIS AUGMENTED REALITY DENGAN METODE MARKER AUGMENTED REALITY
}

\author{
Awang Harsa $\mathbf{K}^{1)}$, Andi Yusika $\mathbf{R}^{2)}$, Bagus Satria ${ }^{3)}$ \\ ${ }^{1,2,3}$ Teknik Informatika, STMIK Widya Cipta Dharma \\ 1,2,3 Jl. M. Yamin No.25, Samarinda, 75123 \\ E-mail : awangkid@gmail.com ${ }^{1)}$,yu5h1k4@gmail.com ${ }^{2}$, bagoezsatria182@gmail.com ${ }^{3)}$
}

\begin{abstract}
ABSTRAK
Siswa SMP merasa kesulitan dalam memahami materi bangun ruang, karena tanpa alat peraga mereka hanya mampu membayangkan saja atau mengimajinasikan sendiri objek bangun ruang tersebut. Karena itu dibutuhkan aplikasi yang dapat menampilkan bentuk bangun ruang 3 dimensi agar siswa dapat memahami bentuk dari masing-masing bangun ruang.

Pembelajaran bangun ruang berbasis augmented reality dengan metode marker augmented reality adalah aplikasi multimedia yang menggabungkan data grafis bentuk bangun ruang 3 dimensi dengan media buku. Menampilkan bangun ruang seperti kubus, balok, prisma, limas, tabung, kerucut, dan bola, beserta elemen-elemen dan rumus-rumus yang berlaku pada bangun ruang tersebut. Dengan metode marker augmented reality yang mengidentifikasi pola dari marker untuk menampilkan objek virtual kedunia nyata.

Dengan menggunakan tahapan pengembangan multimedia yaitu concept, design, material collecting, assembly, testing, dan distribution agar dalam membangun pembelajaran bangun ruang berbasis augmented reality dengan terstruktur. Aplikasi ini dapat menjadi salah satu media pembelajaran alternatif materi bangun ruang untuk tingkat SMP.
\end{abstract}

Kata Kunci: ARToolkit, Blender, Augmented Reality, Pembelajaran, Bangun Ruang.

\section{PENDAHULUAN}

Bangun ruang adalah salah satu materi pelajaran dalam matematika. Setiap jenis dari bangun ruang memiliki bentuk dan juga rumus luas dan volume masing-masing, sehingga banyak siswa yang tidak merasa tertarik untuk mempelajari bangun ruang karena merasa kesulitan karena tidak mengetahui secara pasti bagaimana bentuk dari masing-masing bangun ruang tersebut.

Untuk memenuhi tuntutan tersebut sejalan dengan perkembangan ilmu pengetahuan dan teknologi, khususnya dalam bidang pendidikan, penggunaan media pembelajaran menjadi semakin beragam dan interaktif, salah satunya yang sedang marak saat ini adalah dengan memanfaatkan teknologi Augmented Reality (AR).

Augmented Reality (AR) adalah bidang penelitian komputer yang menggabungkan data grafis $3 \mathrm{D}$ dengan dunia nyata atau dengan kata lain realita yang ditambahkan ke suatu media. Media ini dapat berupa kertas, sebuah marker atau penanda melalui perangkatperangkat input tertentu.

Marker Augmented Reality merupakan tipe Augmented Reality yang mengenali marker dan mengidentifikasi pola dari marker tersebut untuk menambahkan suatu objek virtual ke lingkungan nyata. Dengan adanya perpaduan teknologi modern yaitu visualisasi 3D dalam hal ini peneliti menggunakan Augmented Reality, maka bangun ruang yang akan diajarkan guru kepada siswa akan terasa lebih menarik dan membuat siswa dapat memahami bentuk dan rumusrumus dari bangun ruang tersebut.

\section{RUANG LINGKUP PENELITIAN}

Permasalahan difokuskan pada :

1. Bangun Ruang yang akan ditampilkan adalah pelajaran bangun ruang untuk tingkat SMP.

2. Augmented Reality (AR) ini hanya dapat dijalankan dengan menggunakan personal computer dan notebook yang telah memiliki fasilitas kamera digital internal ataupun eksternal.

3. Metode yang digunakan adalah Marker Augmented reality

4. Kemiripan objek 3D yang dibuat disesuaikan dengan personal computer/notebook yang digunakan saat ini.

\section{BAHAN DAN METODE}

Adapun bahan dan metode yang gunakan dalam membangun aplikasi ini yaitu:

\subsection{Augmented Reality}

Menurut Ronald T.Azuma (1997) mendefinisikan Augmented reality sebagai penggabungan benda benda nyata dan maya di lingkungan nyata, berjalan secara interaktif dalam waktu nyata dan terdapat integrasi dan maya dimungkinkan dengan teknologi tampilan yang sesuai, interaktivitas dimungkinkan melalui perangkatperangkat input tertentu, dan integrasi yang baik 
memerlukan penjelasan yang efektif. Sedangkan menurut Stephen Coward dan Mark Faila dalam bukunya yang berjudul Augmented reality a partical guide, mendefinisikan bahwa Augmented reality merupakan cara alami untuk mengeksplorasi objek 3D dan data, AR merupakan suatu konsep perpaduan antara visual reality dengan world reality. Sehingga objek objek virtual 2 dimensi (2D) teknologi AR, pengguna dapat melihat dunia nyata yang ada di sekelilingnya dengan penambahan obyek virtual yang dihasilkan komputer. Dalam buku "Hand Book of Augmented reality", Augmented reality bertujuan menyederhanakan hidup pengguna dengan membawa informasi maya yang tidak hanya untuk lingkungan sekitar, tetapi juga untuk setiap melihat langsung lingkungan dunia nyata, seperti livestreaming video. AR meningkatkan pengguna presepsi dan interaksi dengan dunia nyata.

Menurut penjelasan Haller, Billinghurst dan Thomas (2007), riset Augment Reality bertujuan untuk mengembangkan teknologi yang memperbolehkan penggabungan secara realtime terhadap digital content yang dibuat oleh komputer dengan dunia nyata. Augmented reality meemperbolehkan pengguna melihat objek maya dua dimensi atau tiga dimensi yang diproyeksi terhadap dunia nyata. (Emerging Technologies of Augmented reality).

\subsection{Marker}

Marker merupakan sebuah gambar berpola khusus yang sudah dikenali oleh Template Memory ARToolkit. Dimana marker tersebut berfungsi untuk dibaca dan dikenali oleh kamera lalu dicocokkan dengan template ARToolkit. Setelah itu, baru kamera akan melakukan render objek 3D diatas marker.

Pada umumnya Marker yang bisa dikenali ARToolkit hanya marker dengan pola berbentuk kotak dengan bingkai hitam didalamnya. Akan tetapi seiring berkembangnya zaman banyak pengembang Augmented reality yang dapat membuat marker tanpa bingkai hitam.

\subsection{Marker Augmented Reality}

Menurut Chari (2008) Marker Augmented reality merupakan tipe Augmented reality yang mengenali marker dan mengidentifikasi pola dari marker tersebut untuk menambahkan suatu objek virtual ke lingkungan nyata. Marker merupakan ilustrasi persegi hitam dan putih dengan sisi hitam tebal, pola hitam ditengah persegi dan latar belakang putih. Contoh marker dapat dilihat pada gambar 1 .

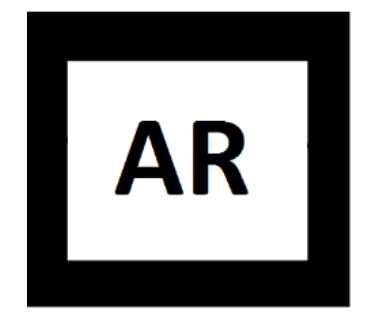

Gambar 1. Contoh Marker

Titik koordinat virtual pada marker berfungsi untuk menentukan posisi dari objek virtual yang akan ditambahkan pada lingkungan nyata. Posisi dari objek virtual akan terletak tegak lurus dengan marker. Objek virtual akan berdiri segaris dengan sumbu $\mathrm{Z}$ serta tegak lurus terhadap sumbu X (kanan atau kiri) dan sumbu Y (depan atau belakang) dari koordinat virtual marker. Ilustrasi dari titik koordinat virtual marker dapat dilihat pada gambar 2 .

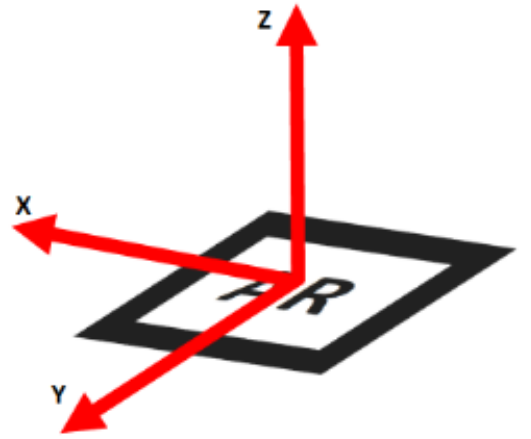

Gambar 2. Titik Koordinat Virtual pada Marker

\subsection{ArtoolKit}

Pengertian ARToolkit secara luas adalah software library untuk membangun Augmented reality dan aplikasi ini adalah aplikasi yang melibatkan overlay pencitraan virtual ke dunia nyata Untuk melakukan hal tersebut, ARToolkit menggunakan cara dengan pelacakan video, agar dapat menghitung posisi kamera yang nyata dengan mengorientasikan pola pada kertas marker secara realtime. Dari semua software library, ARToolkit adalah salah satu software library yang paling klasik dan yang pertama kali dibuat didunia oleh seorang ilmuan Jepang bernama Hirokazu Kato.

ARToolkit memberikan kemudahan dalam penggunaan bagi user yang sedang belajar Augmented reality jika dibandingkan dengan software library lainnya. Selain dari segi kemudahan dalam penggunaannya, ternyata software library ARToolkit juga bersifat open source sehingga siapapun dapat memodifikasi ARToolkit tanpa harus membayar lisensi sepeserpun.

\subsection{Blender}

Blender adalah salah satu software open source yang digunakan untuk membuat konten multimedia khusunya 3Dimensi. Blender memiliki berbagai fungsi antara lain :

1. Blender adalah aplikasi pemodelan tiga dimensi yang dapat membuat sebuah karakter untuk film.

2. Blender memiliki sebuah alat yang kuat untuk pewarnaan permukaan model.

3. Blender memiliki sebuah fasilitas dalam rigging dan animasi yang sangat kuat. Model tiga dimensi yang dibuat dapat dirancang untuk bergerak dan beraksi sedemikian rupa.

4. Blender memiliki mesin rendering sendiri dan dapat dianggap layaknya studio pencahayaan yang lengkap untuk sebuah film.

5. Tidak seperti paket aplikasi 3D lainnya, Blender memiliki compositing module sendiri, sehingga hasil live shoot bisa langsung $\mathrm{di}$ masukkan dan diintegrasikan dengan model tiga dimensi. Blender juga memiliki editor pengurutan video yang unik, sehingga memungkinkan untuk memotong dan mengedit video tanpa harus bergantung pada aplikasi 
pihak ketiga tambahan untuk tahap editing akhir produksi.

6. Selain semua itu, Blender juga memiliki fasilitas Game Engine.

\subsection{Tahapan Pengembangan Multimedia}

Menurut Binanto (2010), metodologi pengembangan multimedia terdiri dari enam tahap (dapat dilihat pada gambar 3), yaitu concept (pengonsepan), design (pendesainan), meterial collecting (pengumpulan materi), assembly (pembuatan), testing (pengujian), dan distribution (pendistribusian). Keenam tahap ini tidak dapat bertukar posisi. Meskipun begitu, tahap concept memang harus menjadi hal yang pertama kali dikerjakan.

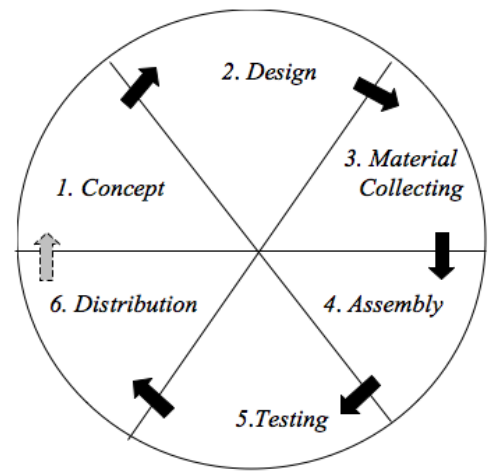

Gambar 3. Tahapan Pengembangan Multimedia

Tahapan Pengembangan Multimedia Meliputi :

1. Concept

Tahapan concept (pengonsepan) adalah tahap untuk menentukan tujuan dan siapa pengguna program (indentifikasi audiens). Tujuan dan penguna akhir program berpengaruh pada nuansa multimedia sebagai pencerminan dari indentitas organisasi yang menginginkan informasi sampai pada pengguna akhir.Karakteristik pengguna termasuk kemampuan pengguna juga perlu dipertimbangkan karena dapat memengaruhi pembuatan desain.

Selain itu, tahap ini juga akan menentukan jenis aplikasi (presentasi, interaktif, dan lain-lain) dan tujuan aplikasi (hiburan, pelatihan, pembelajaran dan lain-lain). Dasar aturan untuk perancangan juga ditentukan pada tahap ini, misalnya ukuran aplikasi, target, dan lain-lain. Output dari tahap ini biasanya berupa dokumen yang bersifat naratif untuk mengungkapkan tujuan projek yang ingin dicapai.

\section{Design}

Design (perancangan) adalah tahap pembuatan spesifikasi mengenai arsitektur program, gaya, tampilan, dan kebutuhan material/bahan untuk program. Spesifikasi dibuat serinci mungkin sehingga pada tahap berikutnya, yaitu material collecting dan assembly, pengambil keputusan baru tidak diperlukan lagi, cukup menggunakan keputusan yang sudah ditentukan pada tahap ini. Meskipun demikian, pada prakteknya, pekerjaan proyek pada tahap awal masih akan sering mengalami penambahan bahan atau pengurangan bagian aplikasi, atau perubahan-perubahan lain.

\section{Material Collecting}

Material Collecting adalah tahap pengumpulan bahan yang sesaui dengan kebutuhan yang dikerjakan. Bahan-bahan tersebut, antara lain gambar clip art, foto, animasi, video, audio, dan lain-lain yang dapat diperoleh secara geratis atau dengan pemesanan kepada pihak lain sesuai dengan rancangannya.Tahap ini dapat dikerjakan secara paralel dengan tahap assembly. Namun, pada beberapa kasus, tahap material collecting dan tahap assembly akan dikerjakan secara linear dan tidak paralel.

\section{Assembly}

Tahap Assembly adalah tahap pembuatan semua objek atau bahan multimedia. Pembuatan aplikasi didasarkan pada tahap design, bagan alir, dan /atau struktur navigasi.

\section{Testing}

Tahap Testing (pengujian) dilakukan setelah menyelesaikan tahap pembuatan (assembly) dengan menjalankan aplikasi/program dan melihatnya apakah ada kesalahan atau tidak. Tahap pertama pada tahap ini disebut tahap pengujian alpha (alpha test) yang pengujiannya dilakukan oleh pembuat atau lingkungan pembuatnya sendiri. Setelah lolos dari pengujian alpha, pengujian beta yang melibatkan penggunaan akhir akan di lakukan.

\section{Distribution}

Pada tahap ini, aplikasi akan disimpan dalam suatu media penyimpanan. Jika media penyimpanan tidak cukup untuk menampung aplikasinya, komprensi terhadap aplikasi tersebut akan dilakukan. Tahap ini juga dapat disebut tahap evaluasi untuk pengembangan produk yang sudah jadi supaya menjadi lebih baik. Hasil evaluasi ini dapat digunakan sebagai masukkan untuk tahap concept pada produk selajutnya.

\section{RANCANGAN APLIKASI}

Perancangan aplikasi pembelajaran bangun ruang berbasis augmented reality ini menggunakan alat bantu flowchart sebagai salah satu cara untuk mempermudah dalam pembuatan aplikasi ini.

1. Flowchart Pembelajaran Bangun Ruang Berbasis Augmented Reality

Alur flowchart dimulai dengan tampilan menu utama "Mulai" dan Tombol Keluar. Saat memilih menu "Mulai" maka Property sheet Properties dari Webcam akan muncul dan pengguna akan mengatur resolusi dari tampilan webcam tersebut. Setelah resolusi telah dipilih maka webcam akan muncul. Lalu pengguna akan menunjukkan marker yang ada pada buku Augmented Reality bangun ruang ke webcam, lalu aplikasi akan melakukan identifikasi marker dan melakukan rendering objek sesuai dengan marker yang ditunjukkan oleh pengguna. Objek bangun ruang 3 Dimensipun akan tampil diatas marker. Untuk menampilkan objek lain 
pengguna hanya menunjukkan jenis marker lain yang terdapat pada buku. Jika sudah maka pengguna bisa keluar program dengan menekan tombol keluar. Seperti yang terlihat pada gambar 4

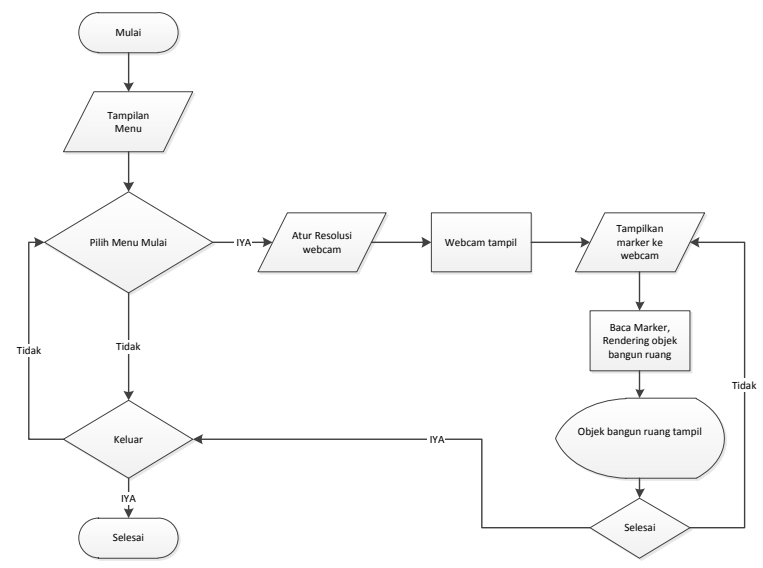

Gambar 4. Flowchart Program

\section{IMPLEMENTASI}

Hasil implementasi berdasarkan analisis dan perancangan adalah sebagai berikut :

1. Marker dalam Pembelajaran bangun ruang berbasis Augmented Reality

Tabel 1. Tabel Marker

\begin{tabular}{|c|c|c|}
\hline No & Marker & Penjelasan \\
\hline 1 & & $\begin{array}{lr}\text { Marker } & \text { kubus } \\
\text { merupakan Marker } & \text { untuk } \\
\text { menampilkan } & \text { objek } \\
\text { kubus 3 dimensi } & \end{array}$ \\
\hline 2 & & $\begin{array}{lr}\text { Marker balok merupakan } \\
\text { Marker } & \text { untuk } \\
\text { menampilkan } & \text { objek } \\
\text { balok } 3 \text { dimensi } & \end{array}$ \\
\hline 3 & & $\begin{array}{lr}\text { Marker } & \text { prisma } \\
\text { merupakan Marker } & \text { untuk } \\
\text { menampilkan } & \text { objek } \\
\text { prisma } 3 \text { dimensi } & \end{array}$ \\
\hline
\end{tabular}

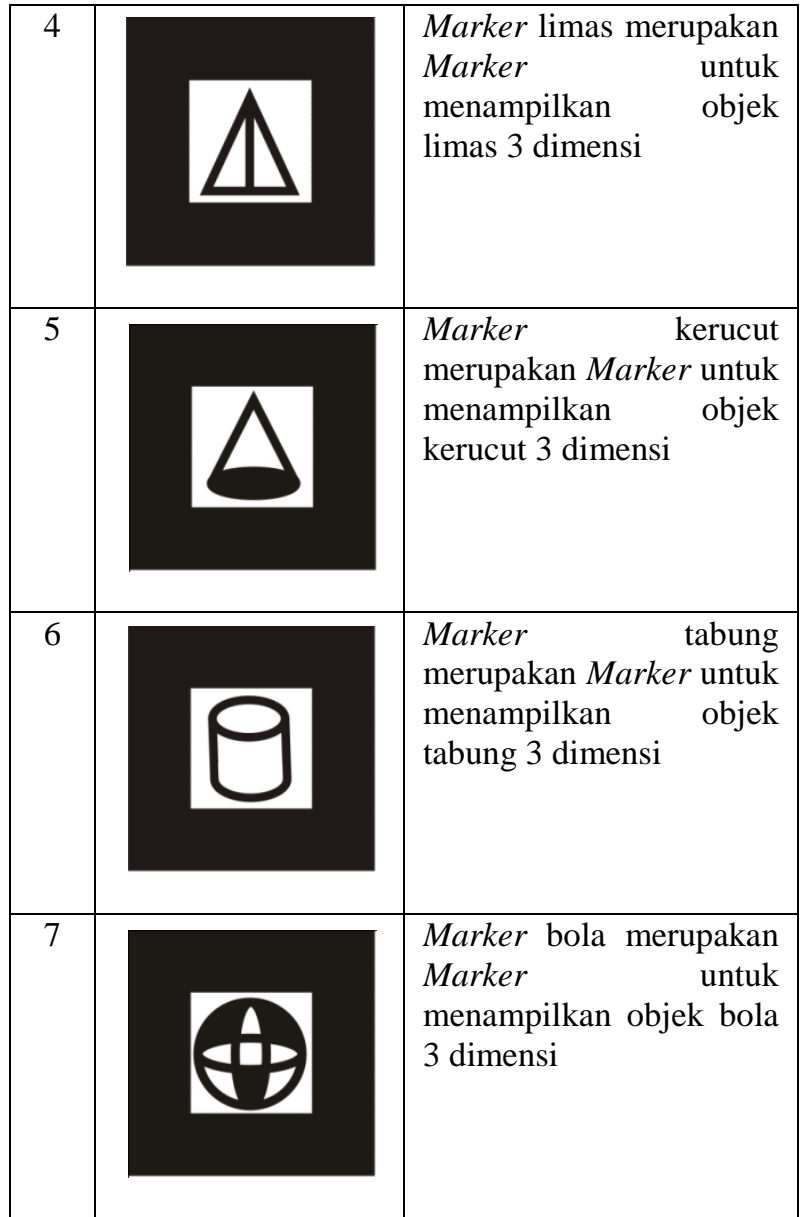

2. Tampilan Menu Utama

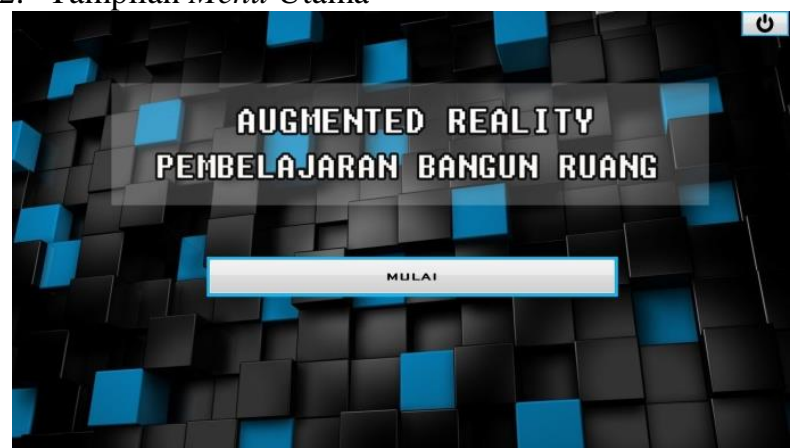

Gambar 5. Menu Utama

Menu utama memiliki 2 tombol yaitu tombol mulai dan tombol keluar. Tombol mulai berfungsi untuk masuk ke webcam dengan aplikasi Augmented Reality. Sedangkan tombol keluar berfungsi untuk keluar dari program. Seperti yang terlihat padaga gambar 5 .

3. Tampilan objek 3 dimensi bangun ruang berbasis Augmented Reality

Objek 3 dimensi bangun ruang memiliki tampilan objek padat, objek terbelah atau rangka objek, elemenelemen dari objek, dan rumus-rumus yang berlaku pada objek tersebut. Objek padat merupakan tampilan dari bentuk objek bangun ruang secara utuh. Objek terbelah atau rangka objek merupakan tampilan untuk menampilkan bagian dalam objek dan diberi keterangan elemen-elemen yang terdapat pada objek tersebut seperti tinggi, panjang, lebar, sisi, jari-jari, dan alas. Rumusrumus yang berlaku pada objek tesebut ditampilkan 
dibagian atas, rumus-rumus yang ditampilkan seperti luas selimut, luas permukaan dan volume. Seperti yang terlihat pada gambar 6 .

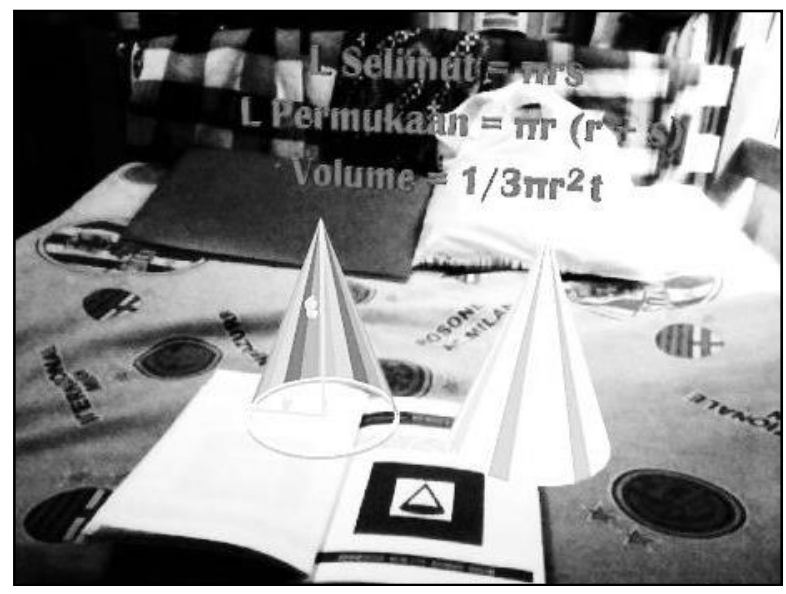

Gambar 6. Tampilan objek 3 dimensi bangun ruang berbasis Augmented Reality

4. Tampilan buku augmented reality bangun ruang

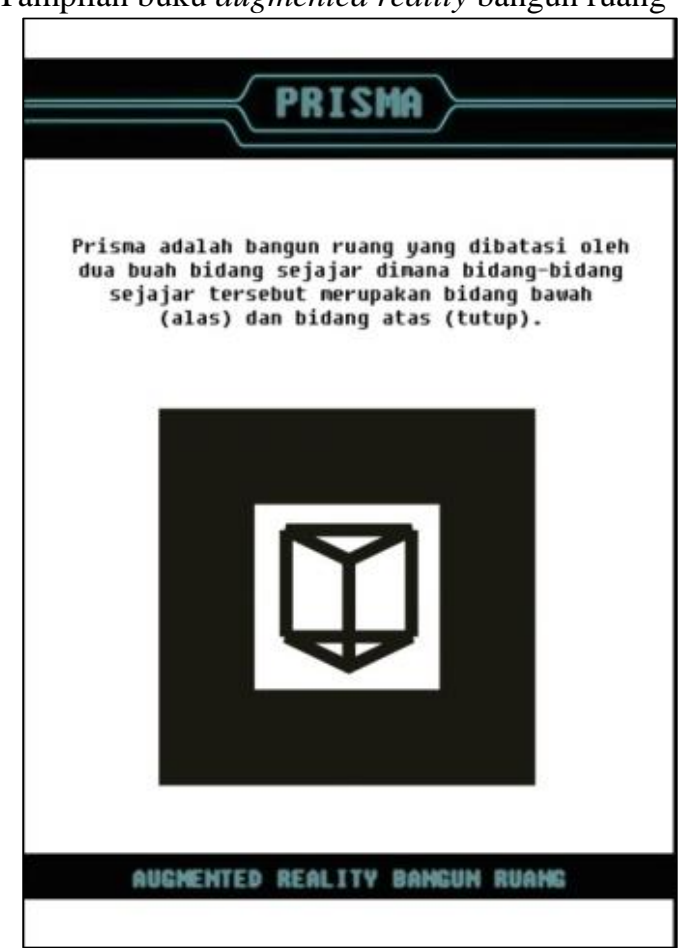

Gambar 7. buku augmented reality bangun ruang

Seperti yang terlihat pada gambar 7 , buku augmented reality bangun ruang menampilkan nama bangun ruang, penjelasan mengenai bangun ruang tersebut, dan marker bangun ruang.

5. Keterbatasan aplikasi pembelajaran bangun ruang berbasis Augmented Reality

Aplikasi pembelajaran bangun ruang berbasis Augmented Reality memiliki beberapa keterbatasan dalam hal pemakaiannya yang dipengaruhi oleh beberapa faktor.
1). Oklusi

Objek virtual hanya akan muncul ketika marker ditangkap kamera. Hal ini membatasi ukuran atau gerakan dari objek virtual. Ini juga berarti bahwa jika pengguna menutupi pola yang ada pada marker dengan tangan mereka atau benda lain, objek virtual akan menghilang.

2). Jarak

Jarak juga menjadi masalah dalam pelacakan optik, ketika marker bergerak menjauhi kamera, mereka menempati lebih sedikit piksel pada layar kamera, dan mungkin tidak cukup detail untuk dapat dengan benar mengidentifikasi pola pada marker.

Dengan menggunakan salah satu marker dari aplikasi pembelajaran bangun ruang berbasis Augmented Reality yaitu marker prisma dengan ukuran yang berbeda yang diuji menggunakan webcam dengan resolusi $640 \times 480$ dan frame rate $30 \mathrm{fps}$. Hasil ini didapatkan dengan menggerakkan marker menjauhi kamera sampai pada jarak tertentu objek virtual 3 dimensi yang berada diatas marker menghilang. Seperti yang terlihat pada tabel 2.

Tabel 2. Tabel jarak Marker

\begin{tabular}{|c|c|}
\hline Marker & Jarak Kamera-Marker \\
\hline Ukuran $(\mathrm{cm})$ & Terjauh $(\mathrm{cm})$ \\
\hline $4 \times 4$ & 45 \\
\hline $6 \times 6$ & 61 \\
\hline $8 \times 8$ & 78 \\
\hline $12 \times 12$ & 117 \\
\hline $16 \times 16$ & 159 \\
\hline
\end{tabular}

3). Marker

Objek virtual akan muncul jika marker berhasil dikenali oleh ARToolkit. Marker yang dapat dikenali adalah marker dengan pola tertentu yang telah dikenalkan/diinputkan pada ARToolkit. Dilakukan pengujian untuk mengetahui apakah marker dapat dikenali jika polanya diputar/dirotasi.

4). Cahaya

Faktor cahaya yang dapat ditangkap oleh lensa kamera juga berperan penting karena apabila menampilakan marker ke kamera pada saat kondisi cahaya gelap/kurang terang, ataupun kondisi cahaya sangat terang/silau maka kamera akan susah dalam mengenali marker dan objek virtual tidak dapat tampil.

\section{KESIMPULAN}

Berdasarkan uraian dari hasil pembahasan maka dapat disimpulkan bahwa pembuatan pembelajaran bangun ruang berbasis augmented reality dengan metode marker augmented reality sebagai berikut :

1. Bangun Ruang yang akan ditampilkan pada aplikasi pembelajaran bangun ruang berbasis augmented reality dengan metode marker augmented reality ini adalah pelajaran bangun ruang untuk tingkat SMP.

2. Aplikasi pembelajaran bangun ruang berbasis augmented reality dengan metode marker augmented reality ini hanya dapat dijalankan dengan menggunakan personal computer atau 
notebook yang telah memiliki fasilitas kamera digital internal ataupun eksternal.

3. Metode yang digunakan adalah Marker Augmented reality

4. Kemiripan objek bangun ruang 3 dimensi yang dibuat disesuaikan dengan personal computer/notebook yang digunakan saat ini.

\section{SARAN}

Berdasarkan hasil dari penelitian ini akan beberapa saran, yaitu sebagai berikut :

1. Aplikasi ini dapat dikembangkan untuk berbagai jenis platform seperti smartphone berbasis android.

2. Menambahkan fitur animasi bergerak 3 dimensi yang lebih menarik agar siswa lebih tertarik belajar melalui aplikasi ini.

3. Dapat menggunakan metode lain seperti markerless.

\section{DAFTAR PUSTAKA}

Andriyadi, Anggi. 2012, Augmented Reality With ARToolkit. Jakarta: NulisBuku.

Bimber, O. 2005, Spatial Augmented Reality Merging Real and Virtual Worlds. A.K Peters Ltd.

Binanto, Iwan. 2010, Multimedia Digital - Dasar Teori dan Pengembangannya. Yogyakarta: Andi.
Chari, dkk. 2008, Augmented Reality Using Over Segmentation : Center for Visual Information Technology, International Institute of Information Technology

Djumanta, Wahyudin. 2008, Belajar Matematika Aktif dan Menyenangkan Untuk SMP/MTS Kelas IX. Departemen Pendidikan Nasional.

Jogiyanto, Hartono. 2007, Analisis dan Desain Sistem Informasi, Edisi III. Yogyakarta: Andi.

Kurniawan. 2014, Matematika untuk SMP/MTs Kelas VIII. Erlangga: Jakarta

Pressman, Roger S. 2010, Software Engineering - A Practitioner's Approach. New York : McGrawHill.

M. Suyanto. 2005, Multimedia Alat untuk Meningkatkan Keunggulan Bersaing. Yogyakarta : Penerbit Andi

Vaughan, Tay. 2011, Multimedia : Making It Work 8th Edition. New York : McGrawHill. 